\title{
The paradox of early intervention: families' participation driven by professionals throughout service process
}

Yoon $\mathrm{H}$ Lee

\author{
Correspondence: \\ yoon.lee@temple.edu \\ Department of Psychological, \\ Organizational, and Leadership \\ Studies in Education, Temple \\ University, 1301 Cecil B. Moore \\ Avenue, Philadelphia, PA 19122, \\ USA
}

\begin{abstract}
Introduction: Early intervention conceived as a program for young infants and toddlers with developmental needs and their families, how early intervention practice establishes family participation in the service process - from referral, evaluation, Individualized Family Service Plan (IFSP) meeting, to service delivery - was considered in this article. Employing disability studies perspectives, the study contends that although families have gained legal rights for family participation in the law, the requirements do not guarantee the quality of family participation. Using a qualitative case study approach, this study looked at both participation and perceptions of families in the early intervention service process in the metropolitan area of the US.
\end{abstract}

Case description: Three families' experience in the process of early intervention was observed, and how these parents reflect on their participation in the development of early intervention service planning and delivery was examined through in-depth interviews.

Discussion and evaluation: Findings showed that the families' participation varied by service providers. The disparity resulted from variable availability, competency levels, and approaches of individual service providers during the service process. In addition, early intervention professionals who are bounded by the requirements in a professional bureaucracy, including the procedural requirements, often impinge on the quality of family participation and limit families' opportunities for quality service provision.

Conclusions: The paper suggests rethinking about how the practice can be implemented. Keywords: Qualitative case study; Disability studies; Parent participation; Early intervention

\section{Background}

Over two decades ago, a special program for young infants and toddlers with developmental delays and disabilities - early intervention - was incepted in the United States. In the ensuing 25 years, one of the program's imperative principles has been to foster young children's learning within the context of families as indispensable members in their lives (Dunst et al. 1991). With a belief that the child spends most of his or her time within the unit of the family, 'families have the opportunity to provide the greatest influence on a child's developing competence' (Bruder, 2000a, p. 108). In employing this principle in practice, the importance of the family unit extended to a further functional practice, i.e., family-centered practice. The underlying principle of familycentered practice is 'viewing the [whole] family as the primary unit of service delivery'

\section{Springer}

(c) 2015 Lee; licensee Springer. This is an Open Access article distributed under the terms of the Creative Commons Attribution License (http://creativecommons.org/licenses/by/4.0), which permits unrestricted use, distribution, and reproduction in any medium, provided the original work is properly credited. 
(Wehman and Gilkerson, 1999, p. 138). Family-centered policies propose that rather than focusing on 'the child' alone, 'the family' becomes the service beneficiary and active deviser of service delivery. Thus, the family has a central role in determining, developing, and making decisions about the services (Garcia et al. 2000. As such, the whole family has an equal status to the service provider in early intervention (Gallagher et al. 2004). In addition, early intervention program suggests families to acquire and build the necessary competence for furthering development of their children with disabilities and their family as a unit (Bailey et al. 2012; Bruder, 2010). For instance, families need to acquire information and advance their knowledge concerning available early intervention services and choices. In so doing, families are able to 'recognize their central and long-term roles in the lives of their children with special needs' (Gallagher et al. 2004, p. 5). Thus, both an equal, active status and partnership and an empowerment of the family's competency are key family-centered approaches.

In order to put this principle of a family-centered approach in practice, a legislative effort was made in the US: the Individualized Family Service Plan (IFSP). The IFSP 'theoretically (a) shows that early intervention is concerned with the whole family and (b) results from a family-centered process of identifying child and family strengths and needs and deciding on intervention priorities' (McWilliam et al., 1998, p. 69). Thus, the completion of IFSP requirements provides a foundation for family-centered early intervention services to children and families within the unit of family. This definition of family-centered early intervention includes an enforcement of parent participation in all aspects of early intervention practices grounded in the law (Wehman and Gilkerson, 1999). More explicitly, 'parents' active participation in the IFSP process [became] a goal of family-centered approaches' (Minke and Scott, 1995, p. 344), and in effect, the completion of the IFSP requirements denotes that the family actively participated in the process of early intervention service planning and delivery. Legitimately, therefore, family-centered early intervention has also been accomplished via the family's active participation in the IFSP procedure and requirements.

Keeping in mind that family participation is an important principle in delivering family-centered early intervention, it is necessary to review what constitutes a quality family participation. A review of the literature identified two arguments: (a) successful collaboration, partnership, or relationship between families and service providers and (b) professionals' understanding families' culture or cultural reciprocity.

In the literature, it is a common principle that the early intervention system is built on the notion of interdependence and collaboration among professionals and families (Dinnebeil and Rule, 1994; Gallagher et al. 1994; James and Chard, 2010; Minke and Scott, 1995; Vohs, 1998; Ziviani et al. 2011). For example, Minke and Scott (1995) investigated 12 different early intervention programs to examine how parents and professionals work together using family-centered models. The results showed that some professionals were doubtful about parents' skills in making decisions. As a result, the study suggested that parental assertiveness and control should be upheld by early intervention practitioners through building supportive relationships. Moreover, Dinnebeil and Rule (1994) found variables that positively and negatively affect collaboration based on their study of 20 parents and 30 professionals, using two structured interview protocols consisting of both open- and close-ended questions. In particular, many parents in the study stressed the importance of interpersonal skills and relationships with 
professionals in collaboration, in addition to establishing rapport with the family. In addition, Zhang et al. (1999) conducted three case studies on three families who participated in an early intervention program and found that early intervention services should consider an individual family's context, e.g., strengths and resources. Using survey and open-ended questionnaires with 248 parents via a mail-in process, Wehman and Gilkerson (1999) also investigated parent perceptions of the benefits, barriers, and improvements needed in the current early intervention system and suggested that 'a collaborative partnership between parents and professionals implies a balance of power between families and service providers [italics added]'. (p. 149). Finally, Summers et al. (2005) defined 'family-professional partnerships as mutually supportive interactions between families and professionals, which focus on meeting the needs of children and families with competence, commitment, equality, positive communication, respect and trust [italics added]' (p. 49). Thus, the level of collaboration, partnership, and relationship is one mode used to show family participation in the field (see also Kontos and Diamond, 2002; Mahoney and Filer, 1996; McWilliam et al., 1995; Sontag and Schacht, 1994).

Additionally, the practice must also be culturally responsive to individual families and there should be a reciprocal understanding by families of the culture of the field (Garcia et al. 2000; Harry et al. 1999; Kalyanpur and Harry, 1999). Studies have argued that the dominant culture in the mainstreamed community inhibit parent-professional partnerships. For example, Harry et al. (1999) studied seven different families from non-mainstreamed culture and their notion of independence in planning services for their child with disabilities. The findings suggested that families contextualized the idea of their child's independence within their cultural context, i.e., a non-mainstreamed context. The authors confirmed that 'culturally appropriate practices' have been positioned within a dominant, mainstreamed setting and suggested that practitioners be flexible and self-reflective when working with families. Garcia et al. (2000) also studied seven mothers of children with communication disabilities who were Spanish speakers of Mexican origin. They found that the participants had different perceptions and beliefs about language disabilities and language acquisition from those of professionals. Rooted in sociocultural theory, the authors contended that the concept of familycentered practices in early intervention must be based on 'respect for and acceptance of each family's ethnicity, culture, language and worldviews' (p. 90). Therefore, it is imperative for service providers to understand what type of cultural context and belief they bring to families who are unfamiliar with the culture of special education (e.g., the legal process, required paperwork, etc.). By and large, 'culture ... enables individual performance' (Artiles, 2003, p. 191). That is, a true understanding of each individual's culture will enable quality family participation.

The literature also describes a persistent lack of quality, active parent participation in early intervention. Regardless of researchers' attempts to render a perfect vision of family participation (Dinnebeil et al. 1999; Kontos and Diamond, 2002; Mahoney and Filer, 1996; McNaughton, 1994; McWilliam et al., 1995; Summers et al., 1990; Summers et al., 2005; Wehman and Gilkerson, 1999; Zhang et al. 1999), the literature attests that there has been limited progress delivering this notion in practice. Early intervention in the United States is overly controlled by federal legislation and its requirements. Special education policy and practice is embedded in unique cultural values and assumptions 
(Kalyanpur and Harry, 1999). In effect, early intervention as a special education program is required to follow a bureaucratic structure that is driven and complied with by law, such as the use of IFSP documents and other related procedures. However, these procedural requirements do not always enhance the outcome of children and students with disabilities. 'Paperwork and bureaucracy were necessary but constant distractions for parents and service coordinators' (Dinnebeil et al. 1999, p. 232). Particularly, service providers 'often prefer to abide by the letter, not the spirit, of the law so that parent participation is more "compliance than communication"' (Kalyanpur and Harry, 1999, p. 25; see also Bailey, 2001). Driven by legal compliance, therefore, questions arise regarding the quality of parent-professional collaboration in early intervention practice. Although legislation guarantees legal rights of parent participation, those requirements do not always yield the quality of parent-professional collaboration. As a result, these legal requirements have affected the quality of parent participation as families' participation in early intervention is given less priority than complying with required documents and other related procedures.

As a former classroom teacher in an early intervention program, I frequently encountered occasions in which I had to participate in and organize meetings with parents and go through an official procedure, such as sharing a testing report, monitoring progress, making transitions to a different placement in order to qualify and provide services for children and families. At numerous meetings, I have observed an unbalanced relationship between families and service providers. On the one hand, administrators and early intervention professionals behave as more knowledgeable, experienced experts who know what works best for children and families. On the other hand, families are also knowledgeable experts concerning what they and their child who is labeled as disabled need. Yet, they are situated with unfamiliar individuals from a school administration who subtly or overtly hold an authoritative position and are pushed to select the best fit for the professionals. Regardless of their agreement or disagreement with opinions, families commonly fine-tune their needs and follow professionals' suggestions in the controlled setting of the meeting surrounded by numerous, knowledgeable professionals. As one of the early intervention team members, I became interested in how families contend with these situations, how they engage in their work with professionals, and how they feel in these controlled atmospheres. In effect, I began to look at examining participation and perceptions of parents when accessing early intervention services while working with their service providers and/or professionals.

\section{Disability studies framework}

Disability studies emerged as a vehicle for critically examining the construction and function of the category 'disability', which has dominated the academic literature in the field of education (Linton, 1998). Most importantly, disability studies explores the critical categorical divisions, such as normal versus abnormal and disabled versus abled, that have come to be treated as 'natural' in contemporary society. Among them, one of the most common binaries is delineating the normal and the abnormal to pigeonhole people with and without disabilities, especially in the field of education. For instance, binary thinking readily separates students into categories and, consequently, demarcates 
educational practices for students with different needs by generating a new educational system, special education. Because of the students' labeled identity that was constructed by categorical thinking, 'society has a responsibility to address them' and their 'problems' via different educational practices and structures (p. 138). Considering these populations as vulnerable and powerless, traditional educators have conceptualized that these students should receive more 'appropriate' special educational services apart from the general education population to 'appropriately' learn and be successful in leading independent lives.

Looking through the lens of disability studies, policymakers or experts also place disability in a categorical position (Bejoian and Reid, 2005). For instance, their assumption is that typically developing children are 'able' to do certain, 'appropriate' tasks while children with disabilities are 'unable' to do them. Similarly, the common thinking in education considers that families of children with disabilities are unable to do certain things that families of children developing typically are able to do when accessing education for their child. Thus, professionals are necessary for those families of children with disabilities to provide support in navigating the educational system and successfully caring for their children. Guided by this perspective, the present study troubled the common thinking concerning how families of children with disabilities are viewed as powerless and vulnerable individuals in practice albeit legislation's intention.

In addition to Disability Studies, Skrtic's (1991a/1991b) critical approach toward special education was employed as a complementary theoretical framework. In describing 'the special education paradox', Skrtic (1991b) claimed that the policies, practices, and grounding assumptions of the special education system are generally driven by the current bureaucratic school organizational structure and specialized professional culture which does not necessarily help meet our social goals of carrying out individualized, equitable education for students with disabilities. Rather, these school organizations and professional practices uphold and maintain the current school structures and, if any, school failures, which inhibit attending to the needs of individuals, while merely categorizing and stigmatizing those with different needs.

According to Skrtic (1991b), the law and its requirements were initially created to carry out individualized and creative services by professionals and practitioners, but it has failed to adhere to its original intent and, in effect, sustains a professional bureaucracy. Therefore, the biggest problem in special education is that the law generally overlooks its initial purpose while it reinforces a bureaucratic configuration in practice. These lawful requirements merely intensify bureaucratic means, especially formalized procedures (e.g., IEPs and IFSPs) and/or rationalized programs, such as inclusive settings, rather than carefully considering students and their individualized needs.

From Skrtic's (1991a, 1991b) perspective on the special education system, this study contended that policy, especially the IFSP requirements, is a product of beliefs that are derived from political parties and their use of knowledge and dominant discourse. Hence, the IFSP process that supposedly exemplifies parent participation procedures and family-centered practices does not necessarily involve parents but positions them as 'others'. Because neither the policy nor its requirements necessarily reflect the voices and needs of parents, the IFSP procedures of early intervention simply intensify bureaucratic means with 'formalized procedures'. By drawing on Skrtic's (1991a, 1991b) institutional and organizational perspectives, this study deconstructed the meaning of the 
law and its procedural requirements that are imposed on families of children with disabilities.

\section{The research}

Driven by legal compliance, questions remain regarding whether and how early intervention practice establishes family participation for children with disabilities and their families. Using a disability studies framework, my belief is that 'although parents gain legal access to the process, legislation does not guarantee the quality of collaboration between parents and professionals' (Valle and Aponte, 2002, p. 474) but rather limits and places parents in a disadvantaged position (Harry, 1992; Valle and Aponte, 2002) and consequently results in less quality family participation in practice. Therefore, a study is needed to closely examine how families go through the legal process of early intervention and interact with their service providers and to carefully listen to the voices of families throughout the process in an attempt to note the quality of the family's early intervention participation. In this way, both families and service providers would be able to better examine the problems in the system and consequently gain insight into possible ways that future practice could be further developed.

This study examined the ways that a group of families engage in the process of early intervention services for their children and how these parents reflect on their engagement in the development of early intervention service planning and delivery (e.g., referral, entry, testing and evaluations, meetings, decision-makings, actual service receiving, etc.). The following research questions guided the study: (a) How do families interact and participate with professionals in the process of accessing early intervention service? (b) How do families reflect on the process of early intervention service while working with their service providers? In studying family participation, my assumption was that professionals' positions of power and the bureaucracy influenced the quality of families' participation and their work with professionals while accessing and receiving early intervention services for their children.

\section{Case description}

\section{Research design}

There has been a range of studies that deconstructed the meaning of parentprofessional partnerships and suggested ways to better build a collaborative, shared relationship (Bailey, 2001; Dinnebeil et al. 1999; Garcia et al. 2000; Harry, 1992; Harry et al. 1999; Kalyanpur and Harry, 1999; Minke and Scott, 1995; Vohs, 1998). However, although the problem has been acknowledged, it has been examined in the field in very limited ways. There has been little research conducted to closely look at relationships, positions of each group, and detailed interactions between families and early intervention professionals. Thus, a study was needed which heeded the interactions and voices of families in this relationship with their service providers by examining each step of the process from gaining access to early intervention services throughout service receiving.

In an attempt to examine families' detailed participation and perceptions in early intervention, this study used a qualitative case study design. Miller (1998) claimed that a theory of research, in other words, the researcher's theoretical framework, provides a powerful rationale for a methodological approach in a study. By undertaking Miller's 
assertion, my theoretical orientation generated the methodological approach of using a qualitative case study. From a disability studies perspective, this study intended to look at both what happens and how families reflect on the process of early intervention services while deconstructing the relationship with service providers and the meaning of the law and its procedural requirements. Because a case study allows closely observing happenings and listening to participants and their perspectives via in-depth interviewing, the methodological approach of a case study was a good epistemological fit and served the purpose of this study. Because families go through and perceive early intervention services within their contextual situation, a qualitative case study helped each family's position and voice to be examined within the context of their individual circumstances (Bogdan and Biklen, 2003).

\section{Participants}

Because my intention was to discover, understand, and gain insight from a particular group of individuals, the study selected a sample from which the most can be learned (Merriam, 1998). After contacting early intervention agencies and service providers, hospitals, and a parent group site in the New York City metropolitan area that consists of diverse populations with distinctive social characteristics, such as ethnicity, race, class, language, and disability, several families who would fit into 'the case' were selected. Within 'the case' that the study delineated, the sample of the families was parents of children who have recently entered the early intervention system. The families had a child from birth to age 3 who was referred to early intervention evaluation and service by the parent or the hospital personnel. Because the study aimed to look at how parents engage in early intervention from the very beginning, my aim was to find families who were at the very earliest stage of establishing early intervention services at the time of recruitment. In that way, the entry process of early intervention as early on as possibly could be examined.

Fewer than ten parents responded to the study's invitation and only half of them fit into 'the case' that was delineated above. Those parents who did not fit into the case had already gone through the early intervention service process or did not qualify for any early intervention service after their evaluation process. Some parents felt that the study required an intensive involvement and decided not to participate. Therefore, the total number of participants in this study was three families. All three families were recruited from an online parent group site. All the families were provided with an informed consent that described their rights in the study's participation, e.g., asking questions, withdrawing from the study, etc. The pseudonyms below were chosen by the families ${ }^{\mathrm{a}}$.

\section{Nora and her family}

Nora and her family were from a white, middle-class, and educated background. Nora has two daughters, who were 2.5 years old and 3 months old at the time of recruitment. Her younger daughter, Ruby, was referred for early intervention due to hypotonia, which is a condition of low muscle tone. Nora's family received physical and occupational therapies after entering early intervention. 


\section{Lily and her family}

Lily was a mother of two boys, who were 3 years old and 4 months old, at the time of recruitment. Lily was from a white, middle-class, and educated family, and her second child, Malcolm, was referred to early intervention. During the first week after his birth, Lily reported that Malcolm had a stroke and later found that he also had colic and hypertonia, which is a condition marked by an abnormal increase in muscle tension and a reduced ability of a muscle to stretch. Lily's family received early intervention services in the disciplines of physical and occupational therapies, special instruction, speech and feeding services, and vision therapy.

\section{KYS $^{\mathrm{b}}$ and her family}

KYS was a mother of two children, a boy (FYS) who was 30 months old and a girl (AYS) who was 3 months old girl, at the time of recruitment. Both children were born prematurely and received early intervention services, including physical and occupational therapies, special instruction, and speech therapies. KYS and her educated, middle-class family members, identified themselves as ethnic minorities - Asian and Central American. Both AYS and FYS had been exposed to Chinese and Spanish as well as English as a primary language spoken at home.

\section{Data}

This study looked at both families' participation and perceptions in the process of early intervention services. The data concerning parent participation were obtained via observation and document review (e.g., IFSP record). The data regarding parent perceptions were collected by means of individual in-depth interviews. Thus, this research utilized three different methods in collecting data: observation, interview, and document analysis.

\section{Observations}

A total of four tofive observations, including one evaluation process, one IFSP meeting, and at least two occasions of service delivery, occurred throughout the data collection period for each participant. Each generally took approximately 45 to $60 \mathrm{~min}$ per observation given that the length of evaluation, meeting, and service receiving generally does not exceed 1 to $1.5 \mathrm{~h}$. The first observation involved an assessment and evaluation procedure at home or center. The second observation occurred at the first IFSP meeting of families which included professionals, service providers, and an official from the New York City Early Intervention Regional Office. Third and fourth observations took place during the service delivery process of early intervention.

As an 'observer as participant', the researcher 'observe[d] and interact[ed] closely enough with members ... without participating in those activities constituting the core of group membership' (Adler and Adler, 1994, p. 380). Because this study intended to examine how families were situated in the process of early intervention service, the interactions and conversations between the families and their service providers were detailed during the observations instead of hindering the interactions via the researcher's participation. The researcher introduced herself to all the members present at the scene and made them aware of her presence. Yet, the researcher did not participate in or 
express her personal opinions in their conversations or activities; rather, the researcher took notes and remained inactive and unobtrusive throughout observations. In addition, observation served 'to provide some knowledge of the context or to provide specific incidents, behaviors, and so on that can be used as reference points for subsequent interviews' (Merriam, 1998, p. 96). Given that observation was carried out before interviewing the families, observing the context especially enabled the researcher to note a descriptive part of the happenings and enlighten ideas for the following interviews.

Field notes recorded the description of the participants and setting, the conversations, detailed description of particular events, especially ones that depicted a relationship between families and professionals and behaviors or responses of families and professionals to those events (Bogdan and Biklen, 2003). Taking into consideration my position as an 'observer as participant' (Adler and Adler, 1994), the description of my own behaviors, actions, and, if any, conversations throughout the observations were included to note their possible effect in my field notes (Bogdan and Biklen, 2003; Merriam, 1998). Additionally, reflective researcher's notes were supplemented immediately after each observation (Bogdan and Biklen, 2003; Emerson et al. 1995).

\section{Interviews}

A series of four in-depth interviews, including one initial interview, two follow-up interviews, and one final interview, was also carried out. An interview length was 30 to 120 min per session which varied by the purpose of the interview. The initial interview primarily focused on building rapport with families; thus, the overall format of the first interview was relatively unstructured and open ended (Fontana and Frey, 1994; Merriam, 1998). The next set of interviews obtained the data that was central to the study. Some more and/or less-structured questions were prepared to explore the details of family participation in early intervention (Merriam, 1998). This set of interviews took place on at least two occasions: i) after the first IFSP meeting and ii) during the service delivery of early intervention within the first 6-month period. The final followup interview mostly focused on examining family reflections on the 'meaning' of early intervention participation/engagement (Seidman, 1998).

Each interview was voice recorded upon obtaining the consent of participants. Transcription followed shortly after the interview. Both selective transcription (or an interview log; see Merriam, 1998) and complete transcription (Dyson and Genishi, 2005) were used. The transcription was also sent to the parents to ensure their agreement on the collected data (Lather, 1986).

\section{IFSP document review}

The IFSP document showed the perspectives of the professionals and the ways that they officially represented their position, communicated, and interacted with families (Bogdan and Biklen, 2003). After obtaining consent from the parents, the first IFSP review was completed after the first IFSP meeting, and the second and the last IFSP review was done toward the end of the data collection, approximately 6 months after the family's entry into early intervention. These data were triangulated in answering the research questions (Merriam, 1998). 


\section{Reflective notes}

Additionally, reflective researcher's notes were used to bring another dimension to the analysis. As an educated, middle-class qualitative researcher of Asian background, I brought in my own assumptions concerning social interactions of two groups, especially employing disability studies perspectives, into the study. It is clear that these assumptions influenced the viewpoint of the observation and interview, and it was important to be conscious of them. Because 'people come into interactions by assuming situational identities that increase their own self-conceptions', the observation was shaped by who I am and what type of identities I perform (Angrosino and Mays de Perez, 2001, p. 689). As Fine (1998) argued, it is imperative to note 'how we [as researchers] are in relation with the contexts we study and with our informants, understanding that we are all multiple in those relations.... [and] how these "relations between" get us "better" data' (p. 135). My reflective notes thus served to understand, decode my multiple identities and positionality, and be aware of my self-conception as a researcher in the data analysis process.

\section{Data analysis}

The first phase of analysis proceeded during the data collection while the entry to early intervention took place. Throughout the entry stage, including referral, evaluation, and the IFSP meeting, data analysis was completed to guide the subsequent data collection as well as to identify preliminary themes among the data (Bogdan and Biklen, 2003). While compiling field notes and transcriptions from each stage, my reflective notes guided what the next data collection activity should observe, ask, or search for. During this analysis phase, significant events that may need to be closely analyzed were noted. From the data collected from observations, interviews, and document analysis, events that highlighted parent-professional interventions were underlined. Particular events were not isolated, but the data was looked over in light of the overall phenomena throughout the early intervention process. Then, similar threads that were emerging were located (Bogdan and Biklen, 2003). As suggested by Miles and Huberman (1994), 'a simple two-level scheme: a more general "etic" level ..., and a more specific "emic" level, close to participants' categories but nested in the etic codes' was used (p. 61). Initially, a list of very general etic-level coding categories from the data, such as interactions, service process events, etc., was established. Then, the categories determining more specific emic-level codes were generated, including: asking questions, responding to questions, delivering information, following the rules, etc.

The second phase involved during and after the data collection procedure. While looking over the events that were initially highlighted during the previous phase, events that would further convey the complexity of how each parent interacted with professionals and negotiated the process were selected. A series of back and forth negotiations occurred while adding and removing key events through reading and rereading the data. Then, through multiple readings of the events, themes or patterns with more interpretative, inferential codes were identified (Miles and Huberman, 1994). This phase was built on from common etic and emic codes that were developed during the first phase of analysis. Bearing in mind these preliminary codes, the data that described the interactions between the families and the service providers were color coded. For 
example, the codes included the following: formalized interaction, compromised parents, one-sided interaction, undervalued parent participation, etc. This process also included examining each family individually as a case. In so doing, some similarities and differences among the families while going through the service process were found. Along with this coding process, my thoughts and reflections were kept track of while engaging in data analysis (Merriam, 1998).

The final phase included compiling the collected data, continuing analytic coding, evolving in-depth analysis of the entire data, and beginning the writing after the completion of data collection. A case study that consisted of each family's significant events was initially created, and then the main events the study intended to focus on were selected within the coding categories. Repeating the process of revisiting the data, the findings of the study gradually evolved. In an attempt to increase the trustworthiness of the study, the parents were asked to read my findings and conclusions during this phase (i.e., member checks; see Lather, 1986). The parents were able to add more descriptive information about their family members and clarify the service process they went through by providing more details. By sharing the study's interpretations with my colleagues during the phase, this triangulation analysis also helped produce a credible study.

\section{Findings}

Findings are particularly intended for addressing two major research questions: (a) How did the families engage in the process of early intervention within the context of their interaction and participation with professionals? (b) How did the families reflect on their interactions and participation in the process of early intervention service? Because the questions focused on how the families engaged in and viewed the early intervention process, the findings included the key events that highlight the families' interactions and participation in the early intervention process from my observation notes and document analysis supported by the interview data. Findings from each case are used to exemplify the study's findings about the families' engagement and reflection on their interactions in early intervention.

\section{Family participation and their varying engagement levels in the process}

Looking through the process of the families' early intervention service from the collected data, including observations, interviews, and document analysis, the events that the families demonstrated varying engagement levels with many early intervention professionals were noted. The differing levels were especially notable in the IFSP meeting process as well as throughout the overall service planning and delivery process with various practitioners. For example, Nora reflected that their physical therapist was harder to communicate with while their occupational therapist was really invested in her work and her clients. Lily recalled that their social worker was not very personable, but their physical therapist had been an advocate for and interacts well with the family as shown in my observation notes. According to the parents, one of the reasons for the difference was the providers' limited time availability. Both Lily and KYS asserted that scheduling could affect their participation level with the therapist, and their frustration with some practitioners had accordingly intensified. 
Among the service providers, in particular, the service coordinator seemed to be the individual who families were closest to, at least for two parents in this study. Both Nora and KYS stated that they have a professional and friendly relationship with their coordinator. Even though the parents related to their coordinators more closely than to other individuals, they all agreed that the coordinators did not play a significant role while the actual procedural requirements were carried out, especially in the IFSP meeting process. Nora reflected that the coordinator was merely the family's 'mailman' who simply delivers the family's words to other people. KYS too reflected,

My relationship with [the service coordinator] is really much more outside of that ... meeting. ... Her job is much more bureaucratic and clerical [in the meeting]. ... it really is up to me to speak up and advocate for my children, ... outside of this she may give me strategies.

KYS then added, '[Even though the coordinator] is not necessarily very proactive ... [she] know[s] all the rules and she's the person telling me the rules'. She generally understood that some services were often dependent on personnel and resources. As such, '[The professionals, including coordinators,] are the people of the insiders. As an outsider, I know there are ways of doing things, so I want to look for the insider'. KYS clearly understood that social resources and parents' past experiences can influence their conscious or unconscious actions and ultimately early intervention activities and practices (Nussbaumer, 2012). She implied that her relationship with her coordinator and early intervention professionals are rather bureaucratic.

Throughout the process of families' engagement with various professionals and officials, all parents agreed that the IFSP meeting was especially too rigid with the process. The process 'was much more about documenting the conference than discussing the conference at the meeting' (Nora). Therefore, these parents requested more understanding from the officials and professionals. Lily claimed:

I would like for all employees who are in contact with families to have some training experience where they hear first-hand accounts of what it's like to realize that your child is anything other than normal and $100 \%$ healthy, .... It's important that they recognize that many of us have just emerged from a traumatic experience ... and that we may require more patience and understanding than your average man on the street.

She added,

Sometimes it seems as though the professionals ... don't really understand how difficult it is for parents to go through the EI process(es).... I have occasionally found myself frustrated by a lack of sensitivity about the realities of time constraints and psychological/emotional and financial resource limitations.

With regard to interactions between families and professionals, KYS concluded, 
The perfect note is being able to convey to the parents that 'I'm trying to be fair, ... [and] be professional, and yet I understand you and ... enough to be able to serve through your anxieties as parents, from concerns that you have due to their prematurity, ... their medical conditions ...' [However] I think it's a hard note to try to strike.

This finding led me to rethink the role of professionals in the early intervention service process. Perhaps professionals especially in the IFSP process who are restricted by rules and regulations may unintentionally limit the scope of families' participation throughout the process. As Lily commented, 'the process ... seems to involve a lot of people - it is bureaucratic'. In that case, the bureaucracy did not positively affect the quality of the families' engagement in the service process.

\section{Reflections: the process informed by many requirements}

All the families concurred that early intervention is a very bureaucratic system. For instance, a waiver needed to be signed in order for Nora's family to carry on an evaluation at the hospital she requested. In the IFSP meeting process, the families especially contended with a professional bureaucracy by adhering to detailed rules and regulations of the law. For example, one notable incident happened when Nora and her family were deciding on a service provision agency for Ruby's early intervention services at their initial IFSP meeting. The family did not know that a service provision agency needed to be decided at the meeting. After discovering this fact, they asked if the decision could be deferred. However, the Early Intervention Official Designee (EIOD) told the parents that if they wait, the services would be pending, thus suggested to start the services and to make a switch, if needed, anytime. The official introduced the parents with the idea that suspending decision-making may result in delaying the services. The parents then accepted and conformed to what was proposed by the official. When reflecting on this incident, Nora contended, 'If there was somebody who should have told us that [rule], ... [it] was our service coordinator'. This comment implied that the coordinator could have better guided the family in the process. In any case, this decision-making process clearly showed how a professional bureaucracy was sustained by the official in accordance with the law and its requirements (Skrtic, 1991b). Nonetheless, Nora was generally content with the outcome of the meeting. Nora supposed that her family might have to 'fight for' services and therefore confessed that she 'kind of' downplayed reporting her child's skills to make sure the services are granted. Throughout the process of her interactions with early intervention officials, Nora understood 'how one has to advocate one side ... [and] negotiate'.

In any event, the parents believed that those constraints are generally exercised by the professionals; the professionals must be accountable for implementation of the requirements. For example, by saying, 'I couldn't say "I don't accept that" [to the official]', KYS admitted that the authority belongs to the official in the early intervention service process. In a similar vein, Lily also expressed a comparable viewpoint in the following interview comment:

The parents are granted many rights, but it seems as though it comes as a bit of a surprise when parents choose to exercise those rights - maybe most don't? The EI representatives I've come into contact with have seemed a little authoritative. 
In addition, Nora said, 'if they say no, ... we'll get it ourselves. ... [But] I don't think I am overdoing it ...' when asked about her prospect regarding an upcoming IFSP meeting. Nora seemed to say that decision-making belongs to the official - whether it is fair or not - and cannot be revoked by the parent.

KYS understood that these officials are bounded by their superiority in the system. When asked for both physical and occupational therapies for her daughter's services, KYS renounced her decision because of the early intervention rules as stated by the evaluators. According to KYS, the evaluators said, 'It's my professional opinion that she [AYS] needs [both therapies] ... [But] the EIOD would get really [upset] at us if we were to make that recommendation'. Thus, KYS believed, 'Professionals who work together know each other's quirks. ... So [that's] may be a reflection of those quirks' and would not do anything that could cause 'conflicts between me and my supervisor'.

In the early intervention process, therefore, many requirements particularly juxtaposed the position between the families and the service providers. Because professionals' practice is bounded by many detailed rules and regulations of the law, a professional bureaucracy is often maintained. As such, officials and professionals in a professional bureaucracy may unintentionally limit quality service provisions to children and families. Some evidence in this study showed how the law had limited a quality participation of the families by their early intervention service providers or officials.

\section{Discussion and evaluation}

While zooming in on the interactions and participation of the families in the entry and delivery process of early intervention services, findings substantiate that a professional bureaucracy (Skrtic, 1991b) considerably affects the early intervention service process. For example, especially in the IFSP meeting process with professionals, the officials had a stronger, more authoritative position while the service coordinator who supposedly should be their advocate seemed to have a rather insignificant, powerless voice. Furthermore, in the decision-making process at the meeting, the parents had little control in making any actual service decision; instead, the officials led and informed the decision for the families by effecting the law's requirements.

These findings are consistent with those of other studies presented in the literature above and further expand the understandings put forth in the literature through a closer examination of the parent perspectives in two ways. With regard to familyprofessional partnership and interaction (research question 1), first of all, this study showed that the qualities identified as those which advance the relationship between families and service providers were persistently lacking (Summers et al., 2005). Particularly in the IFSP meeting process, the parents reflected that there was a limited level of trust, respect, open communication, and equality between the officials and the families. As Nora recalled, the meeting process was simply documenting than discussing with families' needs and concerns. The interaction between the two parties did not present the qualities the families had expected, thus, a lack of the qualities mentioned in previous studies persisted (see also Dinnebeil et al. 1999; James and Chard, 2010; Kontos and Diamond, 2002; Mahoney and Filer, 1996; McNaughton, 1994; McWilliam et al., 1995; Summers et al., 1990; Wehman and Gilkerson, 1999; Zhang et al. 1999; Ziviani et al. 2011). 
Then again, the families in this study added more qualities to the existing list. In their interview, both Lily and KYS professed that they would wish for more emotional and psychological support from early intervention professionals. The families specifically stated their hope that early intervention professionals could help to ease their emotional struggle over having a child with disabilities. Thus, they believed that more could be offered by professionals than simply supplying tangible services for families. Although some past studies highlighted the importance of care in the relationship between families and service providers (Brotherson et al., 2010; Wehman and Gilkerson, 1999), this has not been an extensive view in the literature. This study broadened what 'care' connotes from the perspective of families. In the study, their perception of 'care' included emotional care as well as some practical considerations, such as financial and time constraints that many parents may struggle with by looking after a child with developmental needs. To some extent, this study certainly extended and further fortified particular ideas from previous research.

Another distinctive contribution involves the procedural requirements in the early intervention process (research questions 1 to 2). As purported by early childhood special education (Bailey, 2001; Bruder, 2000b; Dinnebeil et al. 1999; Mahoney and Filer, 1996; Wesley et al. 1997) and disability studies scholars (Kalyanpur and Harry, 1999; Valle and Aponte, 2002), this study suggested that the early intervention procedures for the families were very much policy driven. The officials usually ensured that all the requirements were completed and the meeting procedures were properly executed. Some bureaucratic requirements, such as form completion accordingly by due date, were also observed. As suggested by the studies of Bailey (2001), Dinnebeil et al. (1999), and this study also confirmed that the legislation or policy in early intervention overly restrained the process and consequently distracted the families from further participation in the process. The part of the family participation requirement is usually carried out by more 'compliance' by the law than 'communication' between families and professionals (Kalyanpur and Harry, 1999). In other words, families may have legal rights for their active participation in the process but are not always offered quality participation (Valle and Aponte, 2002).

Studies in the past mostly claimed that parents were more bounded by policy in determining the types of services or available resources (Mahoney and Filer, 1996; McWilliam et al., 1995; Wesley et al. 1997). These studies contended that resource availability determined by the state and local legislation steered the scope of families' services in the process. A similar account was claimed in this study as KYS understood that early intervention services can be dependent on personnel and resources. On the other hand, the present study explored the types of policy constraints as well as how those constraints operated in the actual process. In the study's instances, the families were mostly able to obtain needed services and were not necessarily limited by resource availability as discussed in the previous studies. The families were asked to voice their needs, concerns, and thoughts in the process; thus, their participation was encouraged by heeding their voice.

\section{Conclusion}

Albeit its small sample, this study suggested that more detailed procedural requirements inhibited the facet of the families' decision-making and consequently affected the 'quality' of engagement and interaction with their early intervention professionals. According to a disability studies' and Skrtic's (1991b) viewpoints, the law and its 
procedural requirements were designed to better complete individualized, creative services by professionals for families of children with disabilities. However, the process implemented by professionals who are bounded by the requirements in a professional bureaucracy may lead them to limit quality service provision purposefully or unintentionally to children with disabilities and their families. Thus, bureaucratic procedures and requirements played a part in the present study; this contention was additionally seen when those constraints were undertaken by the professionals who were accountable for the implementation of the policy in practice as examined via the families' perceptions.

\section{Implications}

\section{Implications for practitioners}

Findings can be applied to practitioners, including actual service providers, evaluators, administrators, etc. The study's findings showed that an over-emphasis on the requirements of the law limited families' quality, individualized participation, and interaction in early intervention. However, the focus in early intervention should be on the family, who is intended to be at the center of attention, rather than on the procedure. To better achieve this goal, echoing Skrtic's (1991b) viewpoint, educators should regard the initial intention of the law and further individualize the procedural process for each child and family. For example, early intervention professionals should examine the intention of the early intervention process, especially the IFSP procedure. The law initially hoped to involve and carefully listen to families in the developmental process of service accessing, planning, and delivery. Thus, the IFSP process should generate an opportunity for stakeholders (e.g., families, service providers, administrators) to better communicate and converse with each other. The IFSP procedure should not merely involve compliance with paperwork but should further individualize services by way of considering the child and the family's quality participation.

To do so, first of all, quality includes emotional care, understanding family's individual circumstances, and being more knowledgeable about how to interact with families of children with disabilities. As asserted by Lily, practitioners should be more aware of the realities of families' limitations. Professionals should actively listen to families and deliver a close, personal approach. As such, teacher and professional development programs should offer training where practitioners hear first-hand accounts of families of children with medical and developmental support.

Secondly, professionals should also open up the scope of participation families are asked to generate by creating a dialog space and bettering the quality of interactions with families, rather than being bounded by required restrictions. More pragmatically, both Nora and KYS hoped that the service coordinator who was intended to be a parent advocate could be more involved or play a larger part with more power in the process. Nora contended that her service coordinator should have better guided the family in the process. KYS also believed that the coordinator who knows all the rules and regulations could be a key player in the process if she becomes more proactive. Therefore, the parents seemed to believe that the service coordinator as a parent advocate should be taking part more meaningfully in the early intervention process. Understanding the importance of service coordination (Bruder, 2000b; Bruder, 2010), this seemed to be a valid argument raised by the families in this study. 


\section{Implications for families}

During their participation, the families seemed to understand the constraints of the early intervention program bureaucracy. Understanding the constraints, both parties - families and professionals - seemed to take part in the process in their own way using their own tactics. For example, Nora downplayed reporting her child's skills to make sure the services are granted. After being in the system for both of her children's services, KYS also learned, 'If you really want something for your child you must ask for it, you must advocate for it'. These families understood a configuration of a professional bureaucracy and implied that parents need to understand how one has to advocate one side and negotiate in this bureaucratic system. For families who will enter the system, therefore, the families implied that parents should understand the system of early intervention bureaucracy and may need to enter into the process of negotiations with professionals. In so doing, the parents would be able to successfully attain needed support services for their child.

\section{Limitations and future research directions}

One limitation of this study pertains to having a limited time for data collection. The study followed the families' engagement in the service process for the first 6 months, including referral, evaluation, IFSP meeting, and actual service sessions. As a result, this study only conveyed the families' early impressions of the early intervention service process. Another limitation occurred in regard to demography. All the participants who were recruited were well educated and living in a middle or upper-middle class neighborhood in an urban area. This trend was due to the limited recruitment and selection process of the participants. Because all the mothers had initiated contact with the researcher for study participation, they were somewhat 'self-selected' participants. Lastly, the purpose of the study necessitated a very narrow focus. My intent was to examine families' participation and perceptions in the early intervention service process. As noted earlier, this purpose was best served with a qualitative case study. Because of my narrow focus, however, the study was not able to further examine the power/knowledge relations between families and professionals. Adding a more comprehensive data analysis method (e.g., discourse analysis) could have deepened the investigation.

In the field of early childhood special education, there has been a limited effort to examine issues and problems of practice in a qualitative way. In the present study, the stories of the families who are the key stakeholders in the early intervention system were narrated. In the future, further effort can be made in narrating the stories of key stakeholders, i.e., all the family members, as well as other stakeholders, such as practitioners, service providers, and officials, in early intervention (Mandell and Murray, 2009). To support a broader line of families' narratives, in addition, future research can consider the range of the families' background representing diverse cultures, languages, disabilities, ethnicities, and social statuses. In so doing, an extended, in-depth examination of the problems and issues in practice would be possible.

\section{Endnotes}

a All families gave their informed consent prior to their participation in the study.

b The parent did not want to use pseudonyms but her and her children's initials. 


\section{Acknowledgements}

The author wishes to thank all the committee members at Teachers College, Columbia University for their help and the families for their participation throughout the course of this study. Particularly, she would like to express her deepest appreciation to Dr. Susan Recchia for her support, guidance, and caring advice throughout the course of revising and rewriting the article.

Received: 9 July 2014 Accepted: 22 March 2015

Published online: 09 May 2015

\section{References}

Adler, PA, \& Adler, P. (1994). Observational techniques. In NK Denzin \& YS Lincoln (Eds.), Handbook of qualitative research (pp. 377-392). Thousand Oaks, CA: Sage.

Angrosino, MV, \& Mays de Perez, KA. (2001). Rethinking observation: from method to context. In NK Denzin \& YS Lincoln (Eds.), Handbook of qualitative research (pp. 673-701). Thousand Oaks, CA: Sage.

Artiles, AJ. (2003). Special education's changing identity: paradoxes and dilemmas in views of culture and space. Harvard Educational Review, 73(2), 164-202.

Bailey, DB. (2001). Evaluating parent involvement and family support in early intervention and preschool programs. Journal of Early Intervention, 24(1), 1-14.

Bailey, DB, Raspa, M, \& Fox, LC. (2012). What is the future of family outcomes and family-centered services? Topics in Early Childhood Special Education, 31(4), 216-223.

Bejoian, LM, \& Reid, K. (2005). A disability studies perspective on the Bush education agenda: The No Child Left Behind Act of 2001. Equity and Excellence in Education, 38, 220-231.

Bogdan, RC, \& Biklen, SK. (2003). Qualitative research for education: an introduction to theory and methods (4th ed.) Boston: Allyn and Bacon.

Brotherson, MJ, Summers, JA, Naig, LA, Kyzar, K, Friend, A, Epley, P, \& Turnbull, AP. (2010). Partnership patterns: addressing emotional needs in early intervention. Topics in Early Childhood Special Education, 30(1), 32-45.

Bruder, MB. (2000a). Family-centered early intervention: clarifying our values for the new millennium. Topics in Early Childhood Special Education, 20(2), 105-115. 122.

Bruder, M. B. (2000b). The Individual Family Service Plan (IFSP). (Eric Digest No. E605), Retrieved from ERIC database. (ED449634)

Bruder, MB. (2010). Early childhood intervention: a promise to children and families for their future. Exceptional Children, 76(3), 339-355

Dinnebeil, LA, \& Rule, S. (1994). Variables that influence collaboration between parents and service coordinators. Journal of Early Intervention, 18(4), 349-361.

Dinnebeil, LA, Hale, L, \& Rule, S. (1999). Early intervention program practices that support collaboration. Topics in Early Childhood Special Education, 19(4), 225-235.

Dunst, C. J., Johanson, C., Trivette, C. M., \& Hamby, D. (1991). Family-oriented early intervention policies and practices: family-centered or not? Exceptional Children, 58, 115-126

Dyson, AH, \& Genishi, C. (2005). On the case: approaches to language and literacy research. New York: Teachers College Press.

Emerson, RM, Fretz, RJ, \& Shaw, LL. (1995). Writing ethnographic fieldnotes. Chicago: University of Chicago Press.

Fine, M. (1998). Working the hyphens: reinventing self and other in qualitative research. In NK Denzin \& YS Lincoln (Eds.), Handbook of qualitative research (pp. 70-82). Newbury Park, CA: Sage.

Fontana, A, \& Frey, JH. (1994). Interviewing: the art of science. In NK Denzin \& YS Lincoln (Eds.), Handbook of qualitative research (pp. 361-376). Thousand Oaks, CA: Sage.

Gallagher, RJ, LaMontagne, MJ, \& Johnson, LJ. (1994). Early intervention: the collaborative challenge. In LJ Johnson, RJ Gallagher, MJ LaMontagne, JB Jordan, JJ Gallagher, PL Hutinger, \& MB Karnes (Eds.), Meeting early intervention challenges: Issues from birth to three. Baltimore, MD: Paul H. Brookes Publishing Co.

Gallagher, PA, Rhodes, CA, \& Darling, SM. (2004). Parents as professionals in early intervention. Topics in Early Childhood Special Education, 24(1), 5-13.

Garcia, SB, Perez, AM, \& Ortiz, AA. (2000). Mexican American mothers' beliefs about disabilities. Remedial and Special Education, 21(2), 90-100

Harry, B. (1992). Restructuring the participation of African-American parents in special education. Exceptional Children 59(2), 123-131.

Harry, B, Rueda, R, \& Kalyanpur, M. (1999). Cultural reciprocity in sociocultural perspective: adapting the normalization principle for family collaboration. Exceptional Children, 66(1), 123-136.

James, C, \& Chard, G. (2010). A qualitative study of parental experiences of participation and partnership in an early intervention service. Infants and Young Children, 23(4), 275-285.

Kalyanpur, M, \& Harry, B. (1999). Culture in special education: building reciprocal family-professional relationships. Baltimore, MD: Paul H. Brookes Publishing Co.

Kontos, S, \& Diamond, K. (2002). Measuring the quality of early intervention services for infants and toddlers: problems and prospects. International Journal of Disability, Development, and Education, 49(4), 337-351.

Lather, P. (1986). Issues of validity in openly ideological research. Interchange, 17(4), 63-84.

Linton, S. (1998). Claiming disability: knowledge and identity. New York: New York University Press.

Mahoney, G, \& Filer, J. (1996). How responsive is early intervention to the priorities and needs of families. Topics in Early Childhood Special Education, 16(4)، 437-457.

Mandell, CJ, \& Murray, MM. (2009). Administrators' understanding and use of family-centered practices. Journal of Early Intervention, 32(1), 17-37.

McNaughton, D. (1994). Measuring parent satisfaction with early childhood intervention programs: current practice, problems, and future perspectives. Topics in Early Childhood Special Education, 14(1), 26-48.

McWilliam, RA, Lang, L, Vandiviere, P, Angell, R, Collins, L, \& Underdown, G. (1995). Satisfaction and struggles: family perceptions of early intervention services. Journal of Early Intervention, 19(1), 43-60. 
McWilliam, RA, Ferguson, A, Harbin, GL, Porter, P, Munn, D, \& Vandiviere, P. (1998). The family-centeredness of individualized family service plans. Topics in Early Childhood Special Education, 18(2), 69-82.

Merriam, SB. (1998). Conducting effective interviews. In SB Merriam (Ed.), Qualitative resource and case study applications in education (pp. 71-93). San Francisco: Jossey-Bass.

Miles, MB, \& Huberman, M. (1994). Qualitative data analysis: an expanded sourcebook (2nd ed.). Thousand Oaks, CA: Sage.

Miller, P. (1998). Some personal reflections on the role of theory in my work. In ME Graue \& DJ Walsh (Eds.), Studying children in context: theories, methods, and ethics (pp. 49-54). Newbury Park, CA: Sage.

Minke, KM, \& Scott, MM. (1995). Parent-professional relationships in early intervention: a qualitative investigation. Topics in Early Childhood Special Education, 15(3), 335-352.

Nussbaumer, D. (2012). An overview of cultural historical activity theory (CHAT) use in classroom research 2000 to 2009. Educational Review, 64(1), 37-55.

Seidman, I. (1998). Interviewing as qualitative research: a guide for researchers in education and the social sciences (2nd ed.). New York: Teachers College Press.

Skrtic, TM. (1991a). Behind special education: a critical analysis of professional culture and school organization. Denver, CO: Love Publishing Company.

Skrtic, TM. (1991b). The special education paradox: equity as the way to excellence. Harvard Educational Review, $61(2), 148-206$

Sontag, JC, \& Schacht, R. (1994). An ethnic comparison of parent participation and information needs in early intervention. Exceptional Children, 60(5), 422-433.

Summers, JA, Dell'Oliver, C, Turnbull, AP, Benson, HA, Santelli, E, Campbell, M, \& Siegel-Causey, E. (1990). Examining the individualized family service plan process: what are family and practitioner preferences? Topics in Early Childhood Special Education, 10(1), 78-99.

Summers, JA, Hoffman, L, Marquis, J, Turnbull, A, \& Poston, D. (2005). Relationships between parent satisfaction regarding partnerships with professionals and age of child. Topics in Early Childhood Special Education, 25(1), 48-58.

Valle, JW, \& Aponte, E. (2002). IDEA and collaboration: a Bakhtinian perspective on parent and professional discourse. Journal of Learning Disabilities, 35(5), 469-479.

Vohs, JR. (1998). Perspective. Infants and Young Children, 11(1), vi-x.

Wehman, T, \& Gilkerson, L. (1999). Parents of young children with special needs speak out: perceptions of early intervention services. Infant-Toddler Intervention, 9(2), 137-167.

Wesley, PW, Buysse, V, \& Tyndall, S. (1997). Family and professional perspectives on early intervention: an exploring using focus groups. Topics in Early Childhood Special Education, 17(4), 435-456.

Zhang, C, Bennett, T, \& Dahl, M. (1999). Family-centered practice in early intervention service delivery: a case study. Infant-Toddler Intervention, 9(4), 331-351.

Ziviani, J, Feeney, R, \& Khan, A. (2011). Early intervention services for children with physical disability: parents' perceptions of family-centeredness and service satisfaction. Infants and Young Children, 24(4), 64-382.

\section{Submit your manuscript to a SpringerOpen ${ }^{\circ}$ journal and benefit from:}

- Convenient online submission

- Rigorous peer review

- Immediate publication on acceptance

- Open access: articles freely available online

- High visibility within the field

- Retaining the copyright to your article

Submit your next manuscript at $\boldsymbol{\nabla}$ springeropen.com 